\title{
An Analysis of the Thermal Conductivity of Composite Materials (CPC-30R/Charcoal from Sugarcane Bagasse) Using the Hot Insulated Plate Technique
}

\author{
René Salgado-Delgado, ${ }^{1}$ Alfredo Olarte-Paredes, ${ }^{1}$ Areli Marlen Salgado-Delgado, \\ Zully Vargas-Galarza, ${ }^{1}$ Teresa Lopez-Lara, ${ }^{2}$ Juan Bosco Hernández-Zaragoza, ${ }^{2}$ \\ Israel Rico-Rodríguez, ${ }^{1}$ and Gonzalo Martínez-Barrera ${ }^{3}$ \\ ${ }^{1}$ Division de Estudios de Posgrado e Investigación del Instituto Tecnológico de Zacatepec, Calzada Tecnológico No. 27, \\ Col. Centro, 62780 Zacatepec, MOR, Mexico \\ ${ }^{2}$ Division de Estudios de Posgrado, Facultad de Ingeniería, Universidad Autónoma de Querétaro, Cerro de las Campanas S/N, \\ Col. de lãs Campanas, 76010 Querétaro, QRO, Mexico \\ ${ }^{3}$ Laboratorio de Investigación y Desarrollo de Materiales Avanzados, Facultad de Química, \\ Universidad Autónoma del Estado de México, Km 12 Toluca-Atlacomulco, 50200 San Cayetano, MEX, Mexico
}

Correspondence should be addressed to René Salgado-Delgado; renesalgado@hotmail.com

Received 11 September 2015; Revised 6 February 2016; Accepted 16 February 2016

Academic Editor: Fernando Lusquiños

Copyright (C) 2016 René Salgado-Delgado et al. This is an open access article distributed under the Creative Commons Attribution License, which permits unrestricted use, distribution, and reproduction in any medium, provided the original work is properly cited.

\begin{abstract}
The production of new thermally insulating composite materials from solid residues such as charcoal from sugarcane bagasse (CSB) is of great importance because it takes advantage of materials that might otherwise pollute the environment. Therefore, for this study, we obtained composite materials based on a portland cement (CPC-30R) matrix and CSB particles with a $4: 1$ water-cement ratio and CSB concentrations of $5 \%, 10 \%$, and $15 \%$ by weight. The thermal conductivities of these materials were characterized following ASTM guideline C177, their CSB morphological properties were analyzed using scanning electron microscopy (SEM), and their compositions were determined using energy-dispersive spectrometer (EDS). The results show that the composite materials have reduced thermal conductivities. The metallic oxide percentage composition of the CSB was also determined. It was observed that there was a reduction in thermal conductivity when CSB was used as compared to $100 \%$ CPC-30R, and the influence of the CSB concentration on thermal conductivity was measured.
\end{abstract}

\section{Introduction}

The increasing concern about industrial pollution has forced the construction and manufacturing industries to seek innovative materials that are trustworthy and sustainable to replace the conventional synthetic fibers used as reinforcements in structural materials. Natural fibers such as sisal, jute, cotton, linen, hemp, and kenaf have been considered as possible alternatives because of their environmental friendliness and their availability in fibrous form and because they can be obtained from plant leaves at a low cost $[1,2]$.
Charcoal from sugarcane bagasse (CSB) is a residue generated by the bagasse burning process that has low pozzolanic reactivity due to its high porosity. This material is frequently used as a fertilizer even though it is inadequate for this use due to its high silica content $\left(\mathrm{SiO}_{2}\right)$ of more than $60 \%$ of the total metallic oxide mass. CSB has a broad and variable particle size distribution in addition to a low nutrient content. Therefore, it is important to promote other uses of CSB that generate an added value and synergistic properties for the material.

The locality of Zacatepec, in the Mexican state of Morelos, has a sugarcane mill. The residues generated by this industry 
accumulate every year, generating a series of negative consequences for both human health and the environment. In addition, this is a waste of a potential source of products. In this study, a composite material was obtained from the agroindustrial residue CSB and used as a reinforcement and matrix for portland cement (CPC-30R).

Various studies on the characterization of composite materials based on cement and various inorganic loads that establish synergistic properties due to the volume and characteristics of the loads are reported. The fillers confer properties such as thermal insulation, light weight, and impact resistance $[3,4]$.

Other studies involve the use of sugarcane bagasse ash, but these differ from the charcoal from sugarcane bagasse. The use of ash does not improve the mechanical strength of the material and water permeability decreases [5].

Our material intends to use the charcoal from sugarcane bagasse to achieve thermal insulation. Bagasse coal has completely different properties to the ash. In ash the organic part is removed leaving only metal oxides.

This method is commonly employed to explain the properties of compounds even though more precise models that include the impact of the shape, size, and distribution of the particles on the elastic properties of the material have been developed $[6,7]$.

The thermal conductivity $(\lambda)$ is a measure of a material's ability to conduct heat. It is most commonly used in Fourier's law of heat conduction. This property is very sensitive to the material's microstructure, and there are thermally conducting and insulating materials.

Fourier's law of heat transfer by conduction states that heat conduction occurs due to a temperature difference between two bodies and obeys the following equation [8]:

$$
\lambda \equiv-\frac{q_{x} \Delta x}{A \Delta T}
$$

where $\lambda$ is the thermal conductivity in watts per meter-degree Celsius $\left(\mathrm{W} / \mathrm{m}^{\circ} \mathrm{C}\right), q_{x}$ is the heat flow in the $x$ direction in watts, $\Delta x$ is the thickness of the sample in meters, $\Delta T$ is the temperature difference in ${ }^{\circ} \mathrm{C}$, and $A$ is the area of the sample in $\mathrm{m}^{2}$.

The method is valid within the linear regime and allows for several material properties, including the thermal conductivity, to be calculated.

\section{Experimental}

2.1. Materials. We used charcoal from sugarcane bagasse (CSB) collected from the "Emiliano Zapata Salazar" sugarcane mill in Zacatepec, Morelos, fast-drying composite portland cement (CPC-30R, "Tolteca" brand), and distilled water from the company "Químicos Farmacéuticos Industriales."

2.2. Equipment. The following devices were used: a Denver Instrument digital scale with a limit of $320 \mathrm{~g}$, certified to meet ISO quality guideline 9001, a Barnant Series 10 mixer, model number 700-5400, granulometry equipment from FIIC, SA de CV A CRODE SCH 000197 drying oven, an insulated hot plate with K-type thermocouples and an Arduino open-source hardware platform, a Thermo Haake

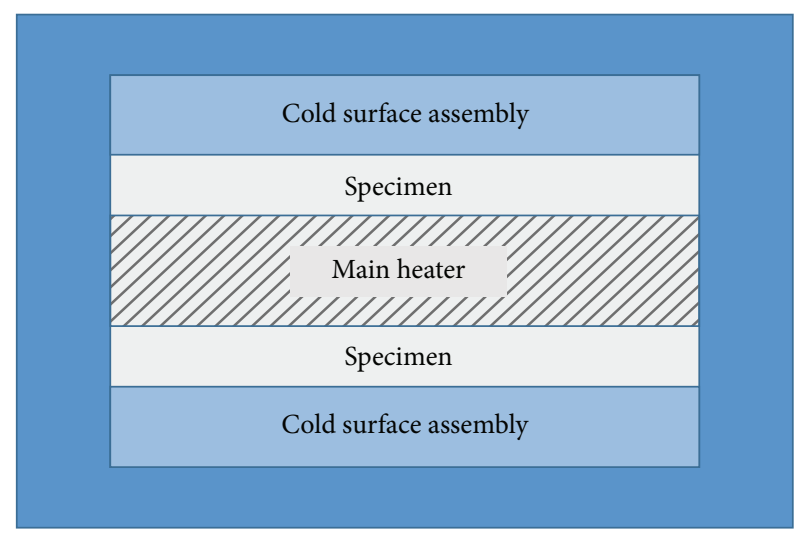

FIGURE 1: System mounting hot isolated plate by ASTM C177-97 standard.

K20 water circulation system, a PID temperature controller with a temperature range of 20 to $300^{\circ} \mathrm{C}$, and JEOL/JSM6010LA scanning electron microscope (SEM) and energydispersive spectroscope (EDS).

\subsection{Methods}

2.3.1. Preparation of the Charcoal from Sugarcane Bagasse (CSB). To eliminate any traces of organic fiber, $250 \mathrm{~g}$ of CSB was placed in the drying oven for 2 hours at $400^{\circ} \mathrm{C}$ and then allowed to cool down. Subsequently, different sizes of CSB particles were separated using the granulometry equipment (mesh 100: $0.150 \mathrm{~mm}$ and mesh 200: $0.075 \mathrm{~mm}$ of hole opening. It is relative with ASTM E11-87).

2.3.2. Preparation of the Composite Materials. The composite materials were prepared by mixing different weight concentrations of $\operatorname{CSB}(5,10$, and $15 \mathrm{~g})$ with cement $(100 \mathrm{~g})$ at a rate of $140 \pm 5 \mathrm{rpm}$ for 5 minutes. Then, water was added $(40 \mathrm{~g})$ and mixed at a rate of $285 \pm 10 \mathrm{rpm}$ for 5 minutes. The mixtures obtained were poured into $10 \times 2.5 \times 2.5 \mathrm{~cm}$ metallic molds. The molds containing the mixtures were left to dry at room temperature for 72 hours. Then, the composite materials were extracted from the molds for characterization.

\subsection{Characterization}

2.4.1. Measurement of Thermal Conductivity. For this study, a hot plate system based on ASTM guideline C177-97 (Standard Test Method for Steady State Heat Flux Measurements and Thermal Transmission Properties by Means of the Guarded Hot Plate Apparatus) was used. Figures 1 and 2 show the experimental setup, which consists of the following elements: a hot plate, samples of the materials, two cold plates, one on each side of the system, a mounting system, an isolation chamber, and the necessary mechanisms for tuning and measurement [9].

Some of the most important specifications in the guideline are as follows: the method must be applied to materials with thermal conductivities of up to $0.62 \mathrm{kcal} / \mathrm{mh}^{\circ} \mathrm{C}$; the temperature during the test must be kept between -45 and 


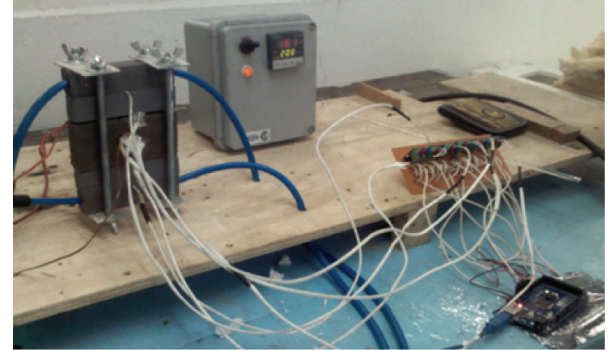

FIgURE 2: System hot insolated plate technique.

$760^{\circ} \mathrm{C}$; the external insulation surrounding the guard ring must have a thermal resistance of at least twice that of the material being tested; the thermocouples must be made from wire with a diameter no greater than $0.57 \mathrm{~mm}$; and finally, the temperature difference between the hot and cold faces of the sample must be at least $22^{\circ} \mathrm{C}[10]$.

2.4.2. Scanning Electron Microscopy (SEM) and Energy-Dispersive Spectroscopy (EDS) Analyses. The morphology and load distribution of the composite materials were studied using the desktop SEM described in the equipment section. It was set to $3 \mathrm{kV}$ and to a magnification of $1000 \mathrm{x}$. The EDS analysis was performed simultaneously under the same conditions to determine the elemental content and chemical composition of the CSB.

\section{Results and Discussion}

The composite materials were used to create a sample matrix ( 2 sizes $\times 3$ weight concentrations), as shown in Table 1 .

To measure the thermal conductivity, the samples were placed on the hot plate apparatus, which maintained a temperature between 30 and $230^{\circ} \mathrm{C}$ for 4 hours, with a flow temperature of $10^{\circ} \mathrm{C}$ at the cold plate. The thermal conductivities of the composite are shown in Figure 3.

The results show the behavior of the thermal conductivity as a function of temperature and the influence of the particle size and CSB concentration. At $122^{\circ} \mathrm{C}$, the thermal conductivity of the pure cement matrix (CPC-30R) was high at $0.358 \mathrm{~W} / \mathrm{m}^{\circ} \mathrm{C}$.

At this temperature, all of the composite materials tested had lower thermal conductivities than the pure matrix; the values were between 0.350 and $0.300 \mathrm{~W} / \mathrm{m}^{\circ} \mathrm{C}$. Between 122 and $180^{\circ} \mathrm{C}$, a decrease in the conductivity due to the CSB load was observed. For one load size (M-200 or M-100), the $10 \mathrm{~g}$ weight concentration marked the threshold for a minimal response because the thermal conductivity increased when the load was decreased (to $5 \mathrm{~g}$ ) and increased (to $15 \mathrm{~g}$ ). This may have been due to its distribution within the cement matrix. When the results of the M-200-15 g and M-100-15g samples were compared, they showed that a larger particle size results in lower conductivity values when the load is constant. The same result was found when comparing the M-200-5 g and M-100-5 g samples. From this, we concluded that a smaller load leads to more efficient heat conduction, a finding that explains the higher conductivities obtained when the CSB particle size was increased [8].
TABLE 1: Composition of composite materials (CBC/CPC-30R/ $\mathrm{H}_{2} \mathrm{O}$ ).

\begin{tabular}{lccc}
\hline Mesh number & CBC $(\mathrm{g})$ & CPC-30R $(\mathrm{g})$ & $\mathrm{H}_{2} \mathrm{O}(\mathrm{g})$ \\
\hline M-100 & 15 & 100 & 40 \\
M-100 & 10 & 100 & 40 \\
M-100 & 5 & 100 & 40 \\
M-200 & 15 & 100 & 40 \\
M-200 & 10 & 100 & 40 \\
M-200 & 5 & 100 & 40 \\
\hline
\end{tabular}

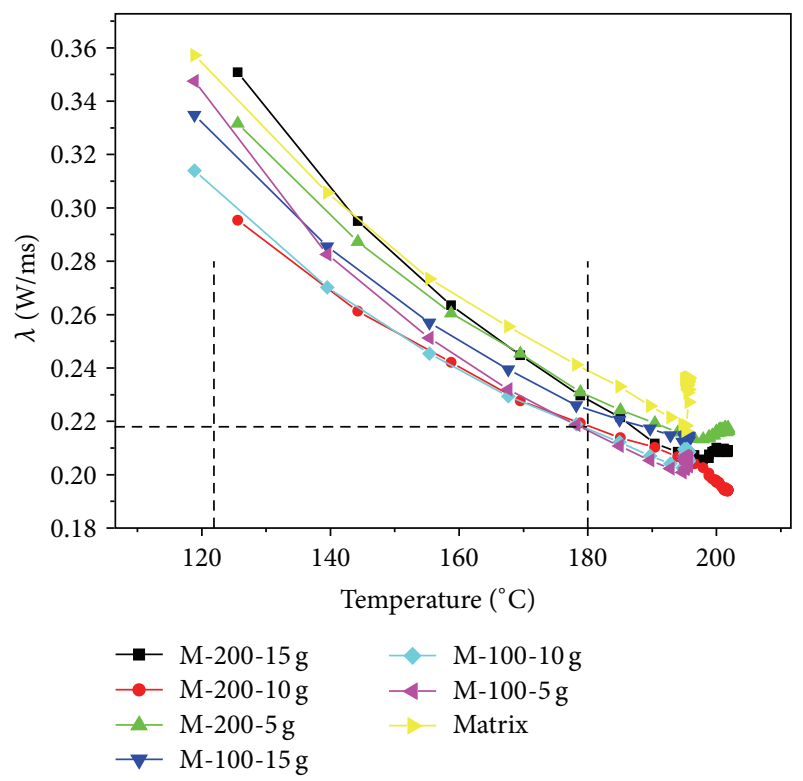

FIGURE 3: Thermal conductivity of composite materials with two sizes (M-100 and M-200) and three concentrations (15, 10, and $5 \mathrm{~g})$ in the range of $120-180^{\circ} \mathrm{C}$.

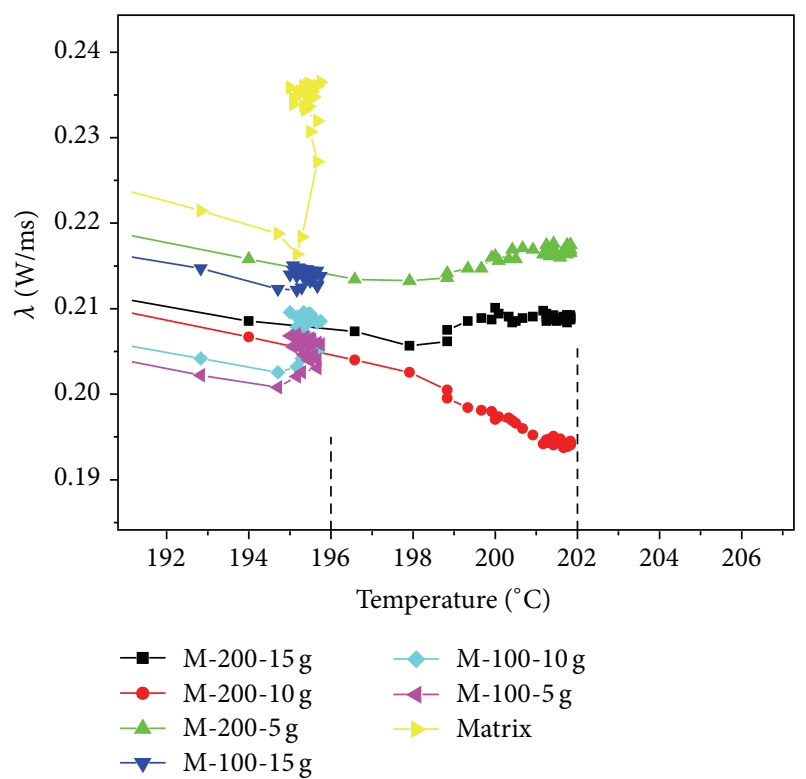

FIGURE 4: Thermal conductivity of composite materials with two sizes (M-100 and M-200) and three concentrations (15, 10, and $5 \mathrm{~g}$ ) in the range of $194-202^{\circ} \mathrm{C}$. 
TABLE 2: EDS: elemental analysis of the CBC.

\begin{tabular}{lcccccccccc}
\hline Chemical formula & $\mathrm{C}$ & $\mathrm{Na}_{2} \mathrm{O}$ & $\mathrm{MgO}$ & $\mathrm{Al}_{2} \mathrm{O}_{3}$ & $\mathrm{SiO}_{2}$ & $\mathrm{P}_{2} \mathrm{O}_{5}$ & $\mathrm{SO}_{3}$ & $\mathrm{~K}_{2} \mathrm{O}$ & $\mathrm{CaO}$ & $\mathrm{PbO}$ \\
$\%$ mol & 70 & 0.32 & 1.58 & 2.31 & 15.89 & 0.66 & 1.53 & 1.93 & 5.57 & 0.21 \\
\hline
\end{tabular}

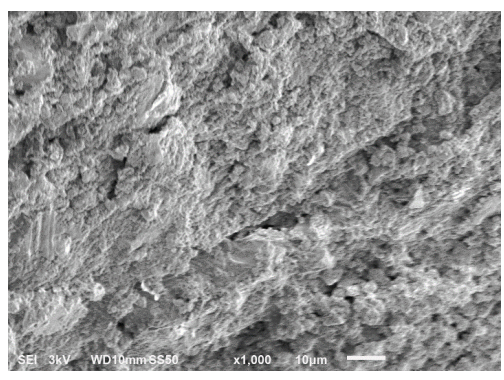

(a)

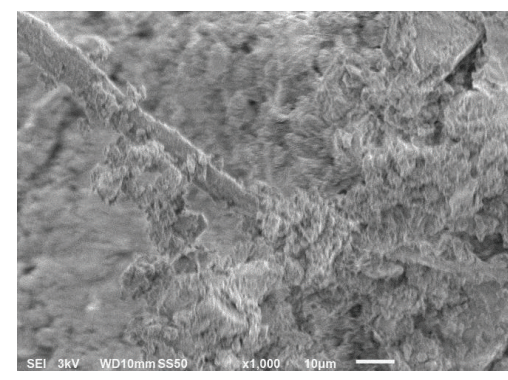

(b)

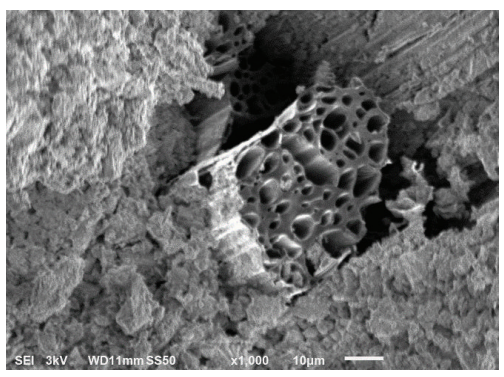

(c)

FIGURE 5: SEM micrographs (1000x) of composite materials: (a) matrix (CPC-30R/ $\mathrm{H}_{2} \mathrm{O}$ ), (b) M-200-10 g, and (c) M-100-10 g.

Figure 4 shows that at $195.5^{\circ} \mathrm{C}$ a maximum conductivity of $0.235 \mathrm{~W} / \mathrm{m}^{\circ} \mathrm{C}$ for the sample was obtained (matrix: portland cement). Samples containing charge (CSB) showed a lower thermal conductivity in the range of 0.215 to $0.205 \mathrm{~W} / \mathrm{m}^{\circ} \mathrm{C}$ at this temperature (the latter being shown for M-200-10 g).

In the temperature range of 196 to $199^{\circ} \mathrm{C}$ the thermal conductivity decreases for all samples with CSB.

The sample M-200-10 g shows the lowest thermal conductivity of $0.194 \mathrm{~W} / \mathrm{m}^{\circ} \mathrm{C}$ at a temperature of $202^{\circ} \mathrm{C}$. The CSB is contributing to having a low thermal conductivity. With a concentration of $10 \mathrm{~g}$ CBS has the lowest income considering that this concentration is critical because by using 200-mesh distributes the load better generating sufficient space for the thermal conductivity decreases. This demonstrates that a good load distribution and a small particle size favor insulating material properties, as explained by Peña-Rodríguez et al., 2008 [8], where the thermal resistivity obtained polystyrene thermal clay loads and the same behavior is observed in the distribution and particle size.

SEM micrographs of the analysis showed that CPC$30 \mathrm{R} / \mathrm{H}_{2} \mathrm{O}$ ratio allows a hardening material without leaving a broken surface (Figure 5(a)). Likewise in the sample M200-10 g good wetting of the matrix on the load can be demonstrated (see Figure 5(b)).

Figure 5(c) shows a particle load in the fracture of the composite material after undergoing strain. It can be seen that part of the load fell off the matrix suggesting a weak interaction between the filler and the matrix. It notes that the porosity of the charge also contributes to the thermal conductivity of composites decreases.

It is important to establish the composition of the CSB. We used EDS analysis, which provided evidence for the amount of carbon and oxides present in the material for that purpose. Table 2 shows the chemical composition of the CSB surface. Oxides contributed to the decrease in the thermal conductivity of the material, and here, $\mathrm{SiO}_{2}$ was present in a greater proportion.

\section{Conclusions}

Composite materials were created using portland cement (CPC-30R) and charcoal from sugarcane bagasse with varying load particle sizes and concentrations. From studying these materials, we concluded that loading diminishes a composite material's thermal conductivity and that increasing the particle size reduces the thermal conductivity. This is because an increase in the particle size affects the heat conduction by decreasing the contact area. Similarly, an increase in the particle size increases the pore size, which may increase the volume of air inside the load and, therefore, reduce the thermal conductivity. The EDS analysis revealed the presence of oxides as an additional factor contributing to the diminished thermal response. The composite material with the lowest conductivity was the M-200-10g sample $\left(0.194 \mathrm{~W} / \mathrm{m}^{\circ} \mathrm{C}\right)$, which behaved as a thermal insulator; it had a reduced heat transfer rate in comparison to the rest of the samples. The conductivity of the M-200-10 g sample was less than the conductivities reported by other authors for ceramic bricks and asbestos plates $\left(0.87\right.$ and $0.36 \mathrm{~W} / \mathrm{m}^{\circ} \mathrm{C}$, resp.). The micrographs show both the porosity of the load and the load-matrix interaction at the point of fracture. In future studies, it is recommended that the effects of thermal shock on the mechanical properties of the materials should be investigated.

\section{Competing Interests}

The authors declare that they have no competing interests.

\section{References}

[1] J. Wei and C. Meyer, "Degradation mechanisms of natural fiber in the matrix of cement composites," Cement and Concrete Research, vol. 73, pp. 1-16, 2015.

[2] F. D. A. Silva, N. Chawla, and R. D. D. T. Filho, "Tensile behavior of high performance natural (sisal) fibers," Composites Science and Technology, vol. 68, no. 15-16, pp. 3438-3443, 2008. 
[3] M. Salas, R. Luco, and R. Ojeda, "Análisis Estructural de un Camarán de materiales compuestos," Anales de Mecánica de la Fractura, vol. 20, 2003.

[4] C. S. Smith, Design of Marine Structures in Composite Materials, Elsevier Science, Amsterdam, The Netherlands, 1990.

[5] Marcos De Paula Oliveira et al., "La caña de azúcarbagazo ash como material parcial- portland-cemento-reemplazo," Dyna, Revista de la Facultad de Minas, vol. 77, no. 163, pp. 47-54, 2010.

[6] N. Martínez-Mateos, D. Busquets-Mataix, M. D. SalvadorMoya, and V. Amigó-Borrás, "Propiedades mecánicas de compuestos de matriz de aluminio reforzados con partículas cerámicas, obtenidos por extrusión de polvos," in Proceedings of the VIII Congreso Nacional de Propiedades Mecánicas de Sólidos, pp. 215-224, 2002.

[7] G. Bao, J. W. Hutchinson, and R. M. McMeeking, "Particle reinforcement of ductile matrices against plastic flow and creep," Acta Metallurgica et Materialia, vol. 39, no. 8, pp. 1871$1882,1991$.

[8] G. Peña-Rodríguez, J. Sánchez-Molina, and R. Monroy, "Efecto de la concentración de poliestireno expandido en la conductividad térmica efectiva de bloques de termoarcilla," Revista Colombiana de Física, vol. 40, no. 2, pp. 285-288, 2008.

[9] M. M. Pérez-Sánchez, R. Centeno-Lara, and F. Lazcano-Serrano, "Desarrollo de un prototipo para la caracterización térmica de los materiales de construcción regionales," Ingeniería, vol. 6, no. 2, pp. 13-22, 2002.

[10] ASTM C 177-97(Standard Test Method for Steady State Heat Flux Measurements and Thermal Transmission Properties by Means of the Guarded Hot plate Apparatus). 

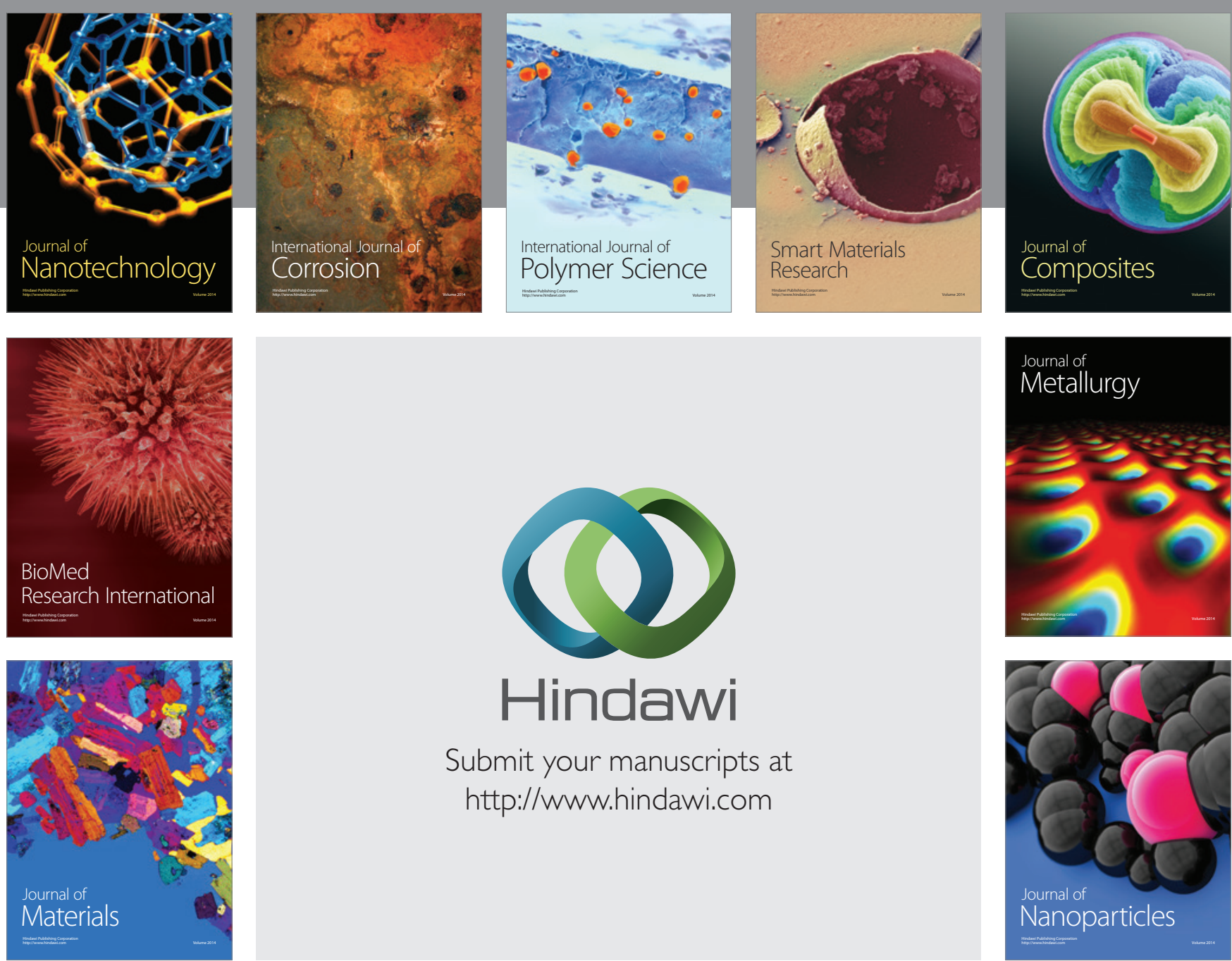

\section{Hindawi}

Submit your manuscripts at

http://www.hindawi.com

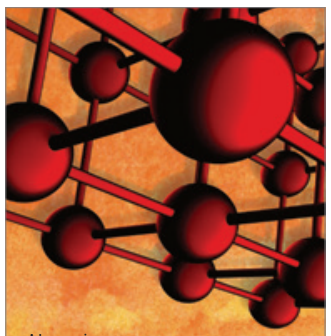

Materials Science and Engineering
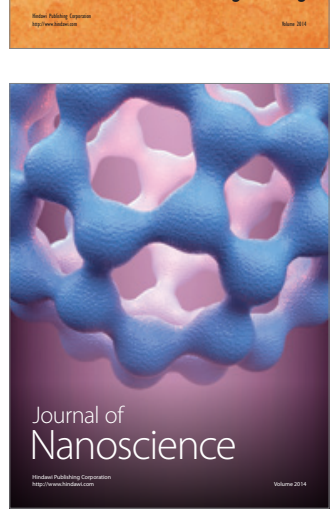
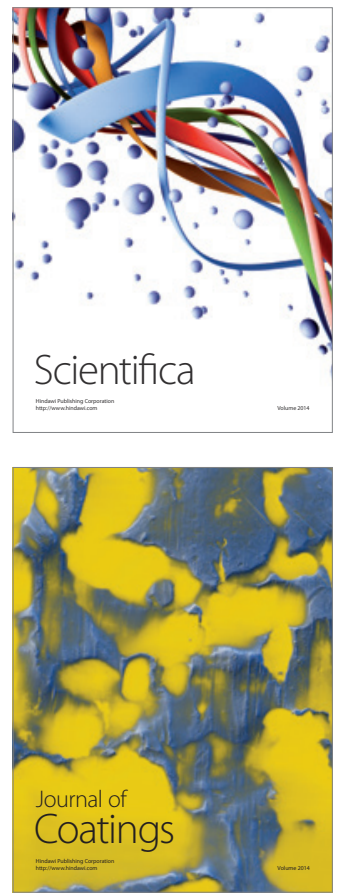
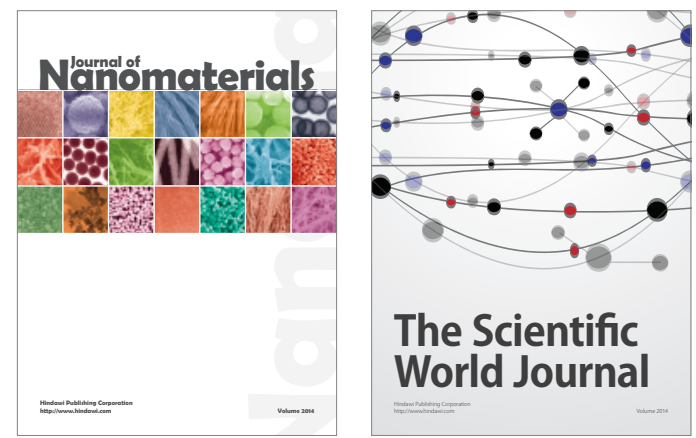

The Scientific World Journal
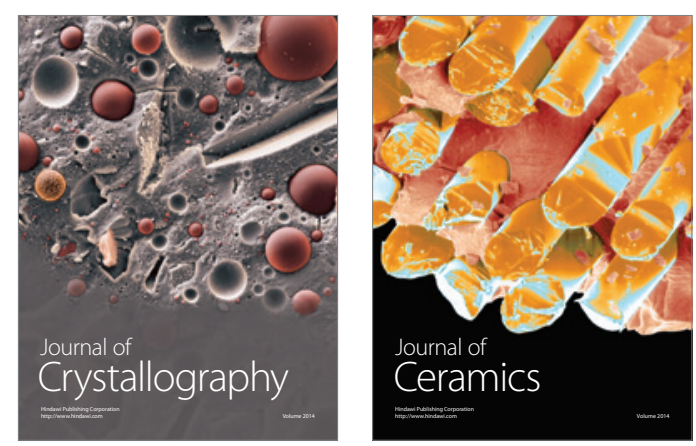
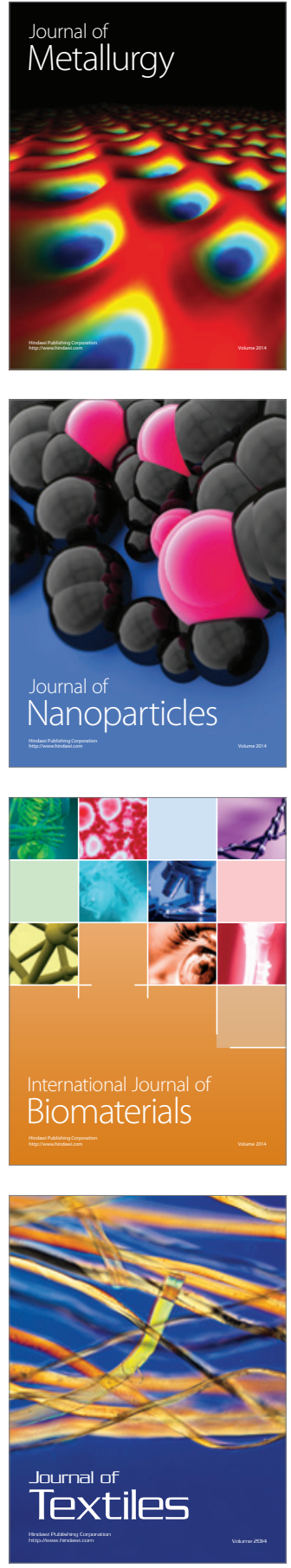